\title{
O TEMPO NO DESFORÇO IMEDIATO
}

\author{
TIME IN THE IMMEDIATE RETALIATION
}

\section{Fagner Vilas Boas Souza ${ }^{1}$}

RESUMO: O desforço imediato deve ser interpretado a luz do regime publicístico, afastando a tese de que a reação estatal deva ser imediata. Não pode haver um prazo indefinido, deve ser fixado um parâmetro que legitime a atuação da Administração Pública e, ao mesmo tempo, faça com que os cidadãos percebam a justeza da providência adotada. A legislação paulista oferece um parâmetro adequado: 6o dias.

Palavras-chave: Administração. Imóvel Público. Invasão. Desforço Imediato. Tempo.

ABSTRACT: The immediate retaliation should be interpreted in the light of the publicistic regimen, setting apart the thesis that the state reaction should be immediate. There cannot be an indefinite deadline, there must be a set parameter that legitimizes the Public Administration performance and, at the same time, allows the citizens to perceive the pertinency of the adopted measure. The São Paulo legislation offers an adequate parameter: 6o days.

Keywords: Administration. Public Property. Invasion. Immediate retaliation. Time.

\section{INTRODUÇÃO}

No fim de $2015^{2}$ a Administração Pública Paulista experimentou um novo desafio: lidar com a invasão de unidades escolares por estudantes da rede pública de ensino.

Independente das razões que tenham levado aqueles jovens a saltar muros e abrigarse por dias a fio nas dependências das escolas, certo é que uma nova realidade se apresentava à Administração.

Pouco antes de deixar seu cargo para passar à equipe do novo governo federal, Alexandre de Moraes, então secretário da Segurança Pública do Estado e hoje Ministro do Supremo Tribunal Federal, oficiou a Procuradoria Geral do Estado formulando consulta a fim de verificar "a possibilidade do Estado de São Paulo fazer cessar esbulho possessório

\footnotetext{
I Procurador do Estado de São Paulo. Mestre em Direito Urbanístico pela Universidade Pontifícia Católica de São Paulo. Especialista em Direito Público e Municipal. Graduado em Direito pela Universidade de São Paulo - USP. E-mail: fagnervb@hotmail.com.
} 
em próprios estaduais valendo-se do desforço necessário previsto no art. 1.210, parágrafo primeiro, do Código Civil, com emprego de força policial proporcional ao agravo"3.

Segundo Moraes, a solução adotada para cessação do esbulho utilizada pelo Estado de São Paulo até então, com o emprego dos interditos possessórios, notadamente de ações de reintegração de posse, com pedido de liminar, tem seu foco obstaculizado por componentes políticos que permeiam as invasões, que por vezes acabam por retardar significativamente a recuperação da posse do próprio estadual, colocando em risco a continuidade dos serviços e atividades públicas essenciais.

À época, Moraes trouxe como referência a ordem de reintegração de posse concedida nos autos de ação de reintegração de posse ${ }^{4}$, a qual não obstante a ordem deferida pelo Juiz do feito foi condicionada pelo Juiz responsável pela central de mandados judiciais ao emprego de força policial desarmada e pessoalmente comandada pelo Secretário da Segurança Pública.

Em resposta, a PGE-SP exarou o parecer 193/2016, da lavra do Dr. Adalberto Robert Alves ${ }^{5}$ assim ementado:

BENS PÚBLICOS. PODER DE POLÍCIA. Autotutela administrativa. Autoexecutoriedade de atos administrativos necessários à manutenção ou retomada da posse, a qualquer tempo, de bens públicos de uso comum e especial. Bens públicos jungidos aos ditames do Direito Público. Inaplicabilidade da restrição temporal estabelecida no §ıํㅡ, do artigo I.210, do Código Civil. Utilização de força policial. Precedentes: Pareceres PA no 29/2008 e GPG/Cons no. 37/2014.

O parecer foi ratificado pelo Procurador Geral do Estado de São Paulo ${ }^{6}$, consignado que:

diante da autêntica banalização nas ocupações de imóveis afetados a serviços públicos no Estado de São Paulo sob o falso pretexto de que se trata do exercício da liberdade de manifestação do pensamento ou do direito de reunião, recomenda esta Procuradoria Geral do Estado que as Secretarias de Estado, agindo em conjunto com a Secretaria da Segurança Pública, alterem a sistemática até aqui adotada, de solicitar a este órgão de advocacia pública a obtenção em juízo de ordens de reintegração de posse"

E, não longe dali, em caso semelhante disse o STJ que o desforço imediato:

3 Conforme Ofício s/n, datado de o6 de maio de 2016.

${ }_{4}^{4}$ Autos no.

5 Procurador do Estado Assessor Chefe da Assessoria Jurídica do Gabinete - AJG.

${ }^{6}$ Dr. Elival da Silva Ramos. 
[...] há de ser visto como obrigação inafastável e de índole vinculada, porquanto inadmissível que se confira ao Administrador optar por defender, ou não, o patrimônio público, o meio ambiente e a regularidade urbanística. Importa ainda

enfatizar que, diante do reposicionamento dos valores e bens que levou a cabo a Constituição de 1988 e a recente legislação urbanístico-ambiental, o desforço imediato não se esgota nas infrações que ponham em risco a segurança ou a saúde pública. $^{7}$

Assim, sedimentou-se que enquanto o agir particular encontra lastro em dispositivo do Código Civil (art. I.210, § $\mathrm{I}^{\mathrm{o}}$ ), a atuação administrativa está respaldada no regime publicístico de seus bens e daí que o particular está adstrito a um requisito temporal ("contanto que o faça logo"), ao passo que a Administração Pública pode exercer seu direito a qualquer tempo.

No entanto, a despeito das posições favoráveis e contrárias ${ }^{89}$ e mesmo das manifestações públicas ${ }^{\mathrm{Io}}$ à nova sistemática, parece que há um ponto a ser aprofundado:

7 Recurso Especial no r.071.74I - SP (2008/o146043-5), disponível em http:// www.planetaverde.org/arquivos/biblioteca/arquivo_20131125205008_241.pdf. Acessado em 28.07.2021.

${ }^{8}$ Não é outra a opinião de Celso Antônio Bandeira de Mello, para quem "pode a Administração Pública promover, por si mesma, independentemente de remeter-se ao Poder Judiciário, a conformação do comportamento do particular às injunções dela emanadas, sem necessidade de um prévio juízo de cognição e ulterior juízo de execução processado perante as autoridades judiciárias", posto que "os interesses defendidos frequentemente não poderiam, para eficaz proteção, depender das demoras resultantes do procedimento judicial, sob pena de perecimento dos valores sociais resguardados através das medidas de polícia”. In: Curso de Direito Administrativo, 26⿳亠丷厂 ed., São Paulo, Malheiros, 2009, pp. 834-835.

9 Conforme publicado em 13 de maio de 2016 pela revista eletrônica Conjur em http://www.conjur.com.br/20ı6-mai-ı3/estado-retomar-imovel-ocupado-aval-judicial-pge-sp: Não há consenso entre especialistas se a administração pública pode promover reintegrações de seus bens sem aval da Justiça. Para o professor de Direito Constitucional da PUC-SP Pedro Estevam Serrano, a autoexecutoriedade só deve ser usada n a impossibilidade da via judicial - o que não ocorre no caso das ocupações de escolas paulistas. Caso contrário, as retomadas de imóveis podem caracterizar abuso de poder. (...) Por outro lado, o professor de Direito Administrativo da Pontifícia Universidade Católica de São Paulo Adilson Abreu Dallari opinou que a administração pública pode, sim, exercer a autotutela para reaver a posse de seus bens. Contudo, ele ressalvou que essa medida deve ser colocada em prática sem excessos.

to Nota pública: Reintegração de posse das escolas. "A OAB/SP vem manifestar preocupação em face do uso de forças policiais, sem autorização judicial, para desocupação de estudantes em escolas públicas, baseando-se o governo do Estado em parecer lavrado pela Procuradoria-Geral do Estado. O Código Civil de fato autoriza que o possuidor possa usar da própria força (autotutela) para fazer parar turbação ou esbulho em sua propriedade, contanto que o faça logo e que a reação seja apenas a necessária para a manutenção ou restituição da posse (art. I2ı, § Io, do Código Civil brasileiro). Esse dispositivo protege tanto patrimônio público, quanto privado. Todavia, ordem de autoridade governamental objetivando o uso da força institucionalizada para a finalidade de reintegração de posse é ato administrativo que se sujeita aos princípios da razoabilidade e proporcionalidade. Em se tratando de invasão pacífica e não predatória, de estabelecimento de ensino oficial, por jovens que lá estudam, parece desarrazoado proceder a reintegração manu militari, sem a prévia cautela de ordem judicial e, assim, levada a efeito da forma menos violenta possível. O próprio Estado Administração ficará também melhor resguardado, e a sociedade civil mais reconfortada. Marcos da Costa. Presidente da OAB/SP”. 
qual a abrangência do "a qualquer tempo" para atuação da Administração? Teria a Administração um prazo indefinido para reaver o bem por suas próprias mãos?

\section{TEMPO COMO FATOR DE LEGITIMAÇÃO}

Tomando emprestada a definição de Habermas, pode-se dizer que a legitimação decorre "da percepção, por parte dos cidadãos, de que as instituições dentro das quais eles vivem são justas, benevolentes e existem no melhor interesse deles, merecedo o seu apoio, sua lealdade e adesão" "I.

Portanto, não se pode esperar que uma atuação estatal, sobretudo quando se estiver a falar da reocupação de próprios públicos, que em boa parte das vezes encontra do outro lado considerável número de pessoas, fique jungida à discricionariedade da própria Adminstração Pública.

A essa altura do desenvolvimento da compreensão do Poder Estatal, mesmo sob o enfoque do poder de polícia, só haverá legitimidade da atuação da Administração se obedecido entre outros o princípio da proporcionalidade ${ }^{12},{ }^{13} q u e$ no Estado de São Paulo, inclusive, vem registrado no art. III, da sua Constituição Estaual, na medida em que a administração pública "obedecerá aos princípios de legalidade, impessoalidade, moralidade, publicidade, razoabilidade, finalidade, motivação, interesse público e eficiência" ${ }^{14}$.

Nem sempre será simples aplicar um princípio. Isso porque, “os princípios jurídicos não prevêem situações determinadas ou efeitos específicos que delas decorreriam. Os princípios, portanto, não estabelecem que, ocorrendo tal fato, será aplicada determinada sanção ou concedido certo benefício”.

\footnotetext{
"HABERMAS, Jürgen Legitimation Crisis. Chapter 6. Theorems of Legitimation Crisis. Boston: Beacon Press, 1975, pp. 68-75

${ }_{12}$ A proporcionalidade "é um importante princípio constitucional que limita a atuação e a discricionariedade dos poderes públicos e, em especial, veda que a Administração Pública aja com excesso ou valendo-se de atos inúteis, desvantajosos, desarrazoados e desproporcionais". In: CUNHA JÚNIOR, Dirley da. Curso de Direito Administrativo. $7^{\mathbf{a}}$ ed. Podium, 2009, p. 50.

${ }^{13}$ A doutrina costuma dividir o princípio da proporcionalidade em três sub-princípios ou requisitos a serem observados: a adequação (ou utilidade), a necessidade (ou exigibilidade) e, por último, a proporcionalidade em sentido estrito.

${ }_{14}$ Constituição Estadual de São Paulo. Disponível em: http://www.legislacao.sp.gov.br/legislacao/ dg280202.nsf/a2dc3f55338oeeof83256cfboosor463/46e2576658bic52903256d63004f305a?OpenDocument. Acessado em 28.07.2021.
} 
Daí que, embora não seja tarefa simples encontrar a quantidade certa de tempo necessário para a execução da retomada do próprio público, esse tempo não pode ser tão abstrato a ponto de se tornar indefinido.

Por isso, diante da invasão de um prédio público por uma ou diversas pessoas, conhecidas ou não, por razões ideológicas ou sem qualquer motivo, não seria nenhum pouco proporcional e, portanto, legítimo o Estado demorar dias, semanas ou até meses para reaver por desforço imediato o seu imóvel.

Não ao tempo indefinido. Não ao prazo indeterminado. Não ao "até que a Administração resolva fazê-lo”. Só assim, os cidadãos terão uma percepção da justeza da atuação estatal e só desta forma a ação será legítima.

\section{TEMPO NA MEDIDA CERTA}

Pelo que se pôde verificar, nos casos posteriores ao Parecer n.193/2016, a retomada do bem público ocorreu dentro do período de 15 a 20 dias, tempo considerado razoável pelas autoridades que acompanharam a ação, considerando o número de pessoas envolvidas (mais de 300 invasores).

Ora, a proporcionalidade, nesses casos, parece ter encontrado sua medida no tempo necessário para que a Administração Pública, em especial a Pasta da Segurança junto com a polícia militar, guarda civil e assistentes sociais necessários planejasse uma operação de retomada adequada e eficiente.

O STJ parece compartilhar a mesma interpretação ao assinalar que:

No que tange à duração do "logo" - isto é, o espaço temporal entre a data do conhecimento e a ação efetiva de desforço -, atuará "logo" a Administração quando imediatamente der início às providências, formais (procedimentais) e materiais (requisição de apoio policial, p. ex.), necessárias à consecução do desforço. ${ }^{15}$

Ou seja, invadido um imóvel por muitas pessoas, evidente que a Administração não poderá utilizar do desforço sem um prévio arranjo de suas Pastas e órgãos competentes, o que importa é o requisito da imediatidade que o caso requer, pois nem sempre a imediatidade poderá ser colocada em exame num cronômetro de horas.

is Recurso Especial no r.071.74I - SP (2008/o146043-5), disponível em http://www.planetaverde.org/ arquivos/biblioteca/arquivo_20131125205008_24I.pdf. Acessado em 28.07.2021. 
Aliás, para entender o enclave temporal disposto nesta norma, deve-se considerar que nem sempre a notícia da turbação ou esbulho guarda instantaneidade em relação ao momento fático da ocorrência, pois o artigo I.224 do Código Civil prevê que para quem não presenciou o esbulho, a posse só é perdida quando este toma ciência deste fato, não importando, por isso, se o esbulho ocorreu por violência, clandestinidade ou precariedade.

Mas qual seria o tempo razoável para a Administração se organizar e executar a retomada? Seria razoável, por exemplo, a Administração demandar cinco ou seis meses para retomar o imóvel?

Se por um lado é bem verdade que seria difícil para não dizer impossível taxar um prazo exato para que a Administração retome o imóvel, por outro, contudo, não parece desarrazoado encontrar um parâmetro de referência que deva ser aplicado pelo menos na maioria dos casos.

Em resposta, e sempre partindo da premissa de que à Administração Pública aplicase regime distinto daquele aplicável ao particular (desforço imediato do art. art. I.21o, § Iํㅡ, do Código Civil), para qual a jurisprudência há tempos vem entendendo como período de poucas horas ou aquele não mais que necessário para a chegada da autoridade policial, os profissionais que atuam na área têm oferecido algumas sugestões.

Para alguns, o prazo já consagrado em boa parte dos Diplomas Processuais ${ }^{16}$ de o5 dias para manifestação ou providência serviria de referência também para a Administração no âmbito das suas atuações.

Contudo, não parece uma opção adequada por duas razões. Primeiro porque o prazo de 05 dias (também conhecido como prazo ordinário, quando não há outro previsto em lei para a sua realização) parece ter cabimento dentro de um processo judicial, onde a relação estabelecida entre as partes e a supervisão da autoridade judicante permitem atuação mais previsível e organizada dentro de possibilidades ou hipóteses previstas em lei. Em segundo, não é difícil imaginar e a realidade demonstra que o5 dias é tempo pouco suficiente para se planejar e executar ações que envolvem distintos órgãos e Secretarias, sobretudo em regiões tão populosas como São Paulo e com tamanho número de invasores, que muitas vezes supera as centenas.

${ }^{16}$ O Novo Código de Processo Civil, por exemplo, traz a previsão do prazo de os dias para uma série de situações, com destaque para o art. $218, \$ 3^{\circ}$, que prevê prazo de 05 dias para a prática de ato processual a cargo da parte, se outro não houver sido determinado por lei ou pelo juiz. 
Uma segunda opinião comum entre aqueles que militam na área de proteção ao patrimônio público, é aquela segundo a qual a Administração Pública disporia do mesmo prazo que os oficiais de justiça têm para cumprir o mandado de reintegração de posse concedida em liminar de ação de reintegração: 15 dias, em São Paulo ${ }^{17}$.

Embora mais apropriada que a solução anterior, a prática não a resguarda. Isso porque, no dia-a-dia das bancas de ações judiciais de reintegração de posse de imóveis públicos no Estado de São Paulo e, em especial, na cidade de São Paulo, o que se tem observado há um bom tempo é que o contato do oficial de justiça com a Procuradoria para que esta comunique a Policia Militar e providencie as estruturas necessárias (caminhões, depósitos etc.) para o cumprimento da ordem vem, em quase todas as vezes, seguido de um segundo contato do mesmo oficial para que a Procuradoria peticione um ou até dois pedidos de prorrogação de prazo junto ao Juiz do feito, tempo necessário para efetivar a reintegração.

Com isso, na prática, o cumprimento da ordem raras vezes é cumprido em período inferior a 40 ou 45 dias.

Uma terceira alternativa ainda é aventada entre os estudiosos do tema ${ }^{18}$. Para 42 pequena parcela deles, a Administração teria o prazo de ano e dia para retomar por suas próprias mãos o imóvel indevidamente tomado. Para eles, o art. 924, do Antigo Código de Processo Civil e agora art. 558, do Novo Código Processual ${ }^{19}$, permitem interpretar que dentro deste prazo a situação de fato não estaria consolidada, podendo remir a posse dos vícios da violência e clandestinidade.

Nesse caso, existe a idéia de que dentro do período de "posse nova", que no processo judicial, inclusive, permite a concessão de liminar de reintegração - rito especial, uma vez

${ }^{17}$ Normas de Serviço dos Ofícios de Justiça da Corregedoria Geral da Justiça de São Paulo. Provimentos ns. 50/1989 e 30/2013, Tomo II, art. 995, Paragrafo $2^{2}$. Disponível em file:/// C:/Users/FAGNER/AppData/Local/Microsoft/Windows/INetCache/IE/67PSU4QB/NSCGJTomoIDJ E.pdf. Acessado em 30.07.2021.

I8 Esse prazo e importante porque contra a posse nova pode o titular do direito lançar mão do desforço imediato (CC. art. $1210, \S^{\circ}{ }^{\circ}$ ) ou obter a reintegração liminar em ação própria (CPC, art. 926 e s.) ou, ainda, a concessão da tutela antecipada. In: DINIZ, Maria Helena. Curso de Direito Civil Brasileiro. Vol. 4, Direito das coisas. São Paulo: Saraiva, 2008. p. 62.

19 “A distinção entre 'posse velha' e 'posse nova', para fins de aplicação da especialização procedimental do Capítulo III do Título III da Parte Especial do novo CPC, é conservada pelo caput e pelo parágrafo único do art. 558, nos mesmos moldes do art. 924 do CPC de 1973.”. In: BUENO, Cassio Scarpinella - Novo Código de Processo Civil Anotado. São Paulo: Saraiva, 2015. p. 379. 
não caracterizada a posse consolidada do invasor sobre o bem, poderia a Administração reaver o bem pelo desforço imediato.

Com o devido respeito àqueles que pensam assim, o referido parâmetro temporal não aparece adequado. $\mathrm{Na}$ verdade, como bem aponta Flavio Tartuce ao citar Whashington de Barros, embora a origem seja obscura, relativamente aos critérios temporais da "posse nova" e da "posse velha", "parte da doutrina aponta que tais prazos têm origem nos costumes, principalmente nos períodos de colheitas" ${ }^{20}$.

Em outras palavras, não parece razoável que diante do perfil urbano das atuais invasões a prédios públicos, com lógica totalmente dinâmica e complexa, em que dezenas de pessoas se organizam rapidamente por meio de aparelhos eletrônicos e outras ferramentas tecnológicas, fosse permitido à Administração Pública demorar ano e dia para se organizar e, por conta própria, reaver o imóvel.

A mesma crítica pode ser apresentada, aliás, para aqueles que defendem prazo indefinido.

Desta forma, é seguro afirmar que a medida ideal para que a Administração atue não deve ser menor do que o necessário para que o aparato estatal se organize internamente, 43 planeje e coloque a postos seus agentes, nem pode ser maior ao de fato percebido pela sociedade como realmente preciso e adequado.

\section{PARÂMETRO ADEQUADO DE TEMPO: 6o DIAS}

Como diz o dito popular: nem oito nem oitenta. Tão desarrazoado como esperar o engendramento de um plano de recuperação de um próprio público pela Administração no exíguo prazo de cinco dias seria conceder-lhe doze meses para tomar as diligências necessárias a garantir a integralidade e segurança do patrimônio público.

Ante as possibilidades de parâmetros, para o Estado Bandeirante, parece que a Lei Estadual n. ${ }^{\circ}$ Io.1 $177^{21}$, de 30 de dezembro de 1998, que regula o processo administrativo no

\footnotetext{
${ }^{20}$ MONTEIRO, Washington de Barros. Curso de Direito Civil. São Paulo: Saraiva. p. 32 apud TARTUCE, Flávio; SIMÃO, Jose Fernando. Direito Civil - Vol. 4 - Direito das Coisas, 5 edição. Método, 2013, p. 45.

${ }^{21}$ ASSEMBLÉIA LEGISLATIVA DO ESTADO DE SÃO PAULO. Lei Estadual no․ ro.177/98. Disponível

em http://www.al.sp.gov.br/repositorio/legislacao/lei/r998/lei-10177-30.12.1998.html. Acessado em 28.07.2021.
} 
âmbito da Administração Pública Estadual Paulista, dentro do capítulo do prazo para a produção dos atos, traz uma alternativa bem apropriada:

Veja, diante da ausência de norma específica que fixe prazo para o desforço imediato pela Administração Pública, o prazo de 6o dias mostra-se plenamente adequado, eis que em obediência aos princípios que regem a Administração Pública (legalidade, impessoalidade, moralidade, publicidade, finalidade e interesse público), em especial a proporcionalidade, e porque muito próximo àquele que ocorre na prática da ordem de reintegração de posse quando concedia em liminar de ação judicial (30 a 45 dias, como assinalado anteriormente).

Ressalte que o desforço imediato não deve ocorrer em 6o dias. Como exposto no parecer 193/2016, o ideal é que ele ocorra o mais rápido possível, muito bom que seja em is ou 20 dias como no caso que suscitou a consulta, por exemplo. Contudo, essa imediatidade não pode ser dissociada de uma percepção realista de um tempo que, em vista das circunstâncias envolvidas, leva em boa parte das vezes até 6o dias.

Assim, dentro da realidade paulista, da prática dos oficiais de justiça do Tribunal de Justiça Bandeirante, do tamanho das Pastas e Órgãos e das peculiaridades e características das invasões, notadamente nas ocorridas recentemente nas unidades escolares estaduais, o 44 prazo de 6o dias se apresenta como adequado parâmetro a legitimar o desforço imediato pela Administração Pública para reaver seus bens invadidos.

E, no mais, parece plenamente aplicável a regra do parágrafo único do referido artigo, segundo a qual "o prazo fluirá a partir do momento em que, à vista das circunstâncias, tornar-se logicamente possível a produção do ato ou a adoção da medida, permitida prorrogação, quando cabível, mediante proposta justificada”.

\section{CONCLUSÕES}

I. A posse é um direito e seu exercício gera efeitos jurídicos, a legislação legítima o possuidor a defendê-la, até mesmo com o uso da força bruta contra turbadores, molestadores e esbulhadores.

II. Enquanto o agir particular encontra lastro em dispositivo do Código Civil (art. I.210, § $\left.\mathrm{I}^{\circ}\right)$, a atuação administrativa está respaldada no regime publicístico de seus bens e daí que o particular está adstrito a um requisito temporal ("contanto que o faça logo"), ao passo que a Administração Pública pode exercer seu direito em tempo distinto. 
III. Não se pode esperar que a atuação estatal, sobretudo quando se estiver a falar da reocupação de próprios públicos que em boa parte das vezes encontra do outro lado considerável número de pessoas, fique jungida às deliberações da Adminstração Pública.

IV. Só haverá legitimidade da atuação estatal se obedecido entre outros o principio da proporcionalidade, só assim, os cidadãos terão uma percepção da justeza da atuação estatal.

V. A Administração não poderá utilizar do desforço sem um prévio arranjo de suas Pastas e órgãos competentes.

VI. O prazo para que a Administração atue não deve ser menor do que o necessário para que o aparato estatal se organize internamente, planeje e coloque seus agentes a postos, nem pode ser maior ao de fato percebido pela sociedade como realmente preciso.

VII. O prazo de 6o dias, previsto no art. I8, da Lei Estadual n.은.177, apresentase como adequado parâmetro a legitimar o desforço imediato pela Administração Pública para reaver seus bens invadidos.

\section{REFERÊNCIAS BIBLIOGRÁFICAS}

ASSEMBLÉIA LEGISLATIVA DO ESTADO DE SÃO PAULO. Lei Estadual no Io.177/98. Disponível em http://www.al.sp.gov.br/repositorio/legislacao/lei/r998/lei10177-30.12.1998.html. Acessado em 28.07.2021.

BUENO, Cassio Scarpinella - Novo Código de Processo Civil Anotado. São Paulo: Saraiva, 2015. CONSTITUIÇÃO ESTADUAL DE SÃO PAULO. Disponível em: http:// www.legislacao.sp.gov.br/legislacao/dg28o202.nsf/a2dc3f55338oeeof83256cfboo501463/46e25 76658bic52903256d63004f305a?OpenDocument. Acessado em 28.07.2021.

CUNHA JÚNIOR, Dirley da. Curso de Direito Administrativo. $7^{\underline{a}}$ ed. Podium, 2009. DINIZ, Maria Helena. Curso de Direito Civil Brasileiro. Vol. 4, Direito das coisas. São Paulo: Saraiva, 2008.

Gi. Estudantes ocupam escola em São Paulo contra fechamento de unidades. Disponível em http://gr.globo.com/sao-paulo/noticia/2015/II/alunos-ocupam-escola-em-sao-paulocontra-fechamento-de-unidades.html. Acessado em 27.07.2021 
HABERMAS, Jürgen Legitimation Crisis. Chapter 6. Theorems of Legitimation Crisis. Boston: Beacon Press, 1975.

MELlO, Celso Antônio Bandeira de. Curso de Direito Administrativo, 26 a ed., São Paulo: Malheiros, 2009.

MONTEIRO, Washington de Barros. Curso de Direito Civil. São Paulo: Saraiva. p. 32 apud TARTUCE, Flávio; SIMÃO, Jose Fernando. Direito Civil - Vol. 4 - Direito das Coisas, $5^{\underline{a}}$ edição. Método, 2013.

SÍTIO ELETRÔNICO. Planeta Verde. Disponível em http://www.planetaverde.org/ arquivos/biblioteca/arquivo_20131125205008_241.pdf. Acessado em 28.07.2021.

TRIBUNAL DE JUSTIÇA DE SÃO PAULO. Normas de Serviço dos Ofícios de Justiça da Corregedoria Geral da Justiça de São Paulo. Provimentos ns. 50/1989 e 30/2013, Tomo II, art. 995, Parágrafo 2 ㅇ․ Disponível em file:///C:/Users/FAGNER/ AppData/Local/Microsoft/Windows/INetCache/IE/67PSU4QB/NSCGJTomoIDJE.pd f. Acessado em 30.07.2021. 